\title{
A DYNAMIC STOCHASTIC GENERAL EQUILIBRIUM (DSGE) MODEL TO ASSESS THE IMPACT OF STRUCTURAL REFORMS ON THE INDONESIAN ECONOMY
}

\author{
Sahminan, Ginanjar Utama, Robbi Nur Rakman, Idham ${ }^{1}$
}

\begin{abstract}
One of the Government programs to spur economic growth is to improve the availability and quality of infrastructure through increased government spending on infrastructure development. In this paper, we build a DSGE model for a small open economy to predict the impact of government spending on output and welfare in Indonesia. The DSGE model uses parameters in line with the characteristics of Indonesian economy. The simulation results show that in the short run a $1 \%$ increase in government spending on consumption and investment could potentially increase economic growth by $0.04 \%$ and $0.05 \%$, respectively. Output multiplier of government spending on consumption is estimated at 0.03 , much lower than output multiplier of the government spending on investment at 0.20 . The simulation results also show that government spending on investment leads to welfare improvement with welfare multiplier at 0.05. On the other hand, an increase in government spending on consumption would lead to a decline in welfare with a multiplier of -0.001 .
\end{abstract}

Keywords: fiscal policy, DSGE, output multiplier, welfare mulipler

JEL Classification: C5, E1

1 The authors would like to thank the head of the Economic and Monetary Policy Department (DKEM), participants of the Research Seminar in DKEM - Bank Indonesia and Aditya Rachmanto for the various inputs provided. The opinions expressed in this paper are those of the authors and do not necessarily reflect those of Bank Indonesia. Corresponding author: sahminan@bi.go.id. 


\section{INTRODUCTION}

One of the most binding constraints facing Indonesia's economy is limited infrastructure in terms of quantity and quality. Such dire conditions are evidenced by the low infrastructure rating of Indonesia. Data from the Global Competitive Index for 2016-2017, for example, shows that the condition of infrastructure in Indonesia ranks 80th, well behind Malaysia and Thailand, which placed 19th and 49th respectively. The low infrastructure rating of Indonesia has been a major constraint to the realisation of robust and sustainable economic growth as well as economic competitiveness in the country. Furthermore, infrastructure limitations have pushed up the cost of logistics, while undermining economic competitiveness and the investment climate in Indonesia.

The main factor behind weak infrastructure in Indonesia has been limited government spending, particularly since the Asian Financial Crisis in 1997/98. Government spending on infrastructure from 2000-2014 averaged around 2\% of GDP, down sharply from 6\% of GDP prior to the crisis (Tabor, 2015). In neighbouring peer countries, the ratio of government spending on infrastructure to GDP is roughly three-times that of Indonesia. Moreover, government infrastructure spending in China and India is approximately 10\% of GDP. ${ }^{2}$ Low government infrastructure spending in Indonesia has been attributed to limited sources of financing and the large burden of subsidies, administrative functions and personnel expenditure.

The Government of Indonesia is currently pursuing a program of structural reforms to stimulate economic performance. ${ }^{3}$ Improving infrastructure through increased spending on investment and less spending on subsidies is part of the structural reform process. Pursuant to the Medium-Term National Development Plan (RPJMN) for 2015-2019, the Government has stipulated the infrastructure targets to be achieved from 2015-2019. A total of 225 infrastructure projects have been upgraded to national strategic projects, covering a broad scope of basic infrastructure, connectivity, electricity as well as communications, water and housing. Furthermore, infrastructure development is not merely restricted to government projects but also involves the private sector through a variety of schemes. Nevertheless, the Government is the dominant investor when striving to achieve the infrastructure development targets set.

Theoretically, larger government investment in infrastructure drives the economy through two channels (IMF, 2014). In the short term, government investment will boost demand through the fiscal multiplier. The impact of government infrastructure investment depends on a range of factors, including economic slack and monetary accommodation. In the medium-long term, however, government investment in infrastructure will affect output from the supply side through increased economic capacity. The demand-side impact of government infrastructure investment depends on the efficiency of that investment.

2 http://www.indonesia-investments.com/business/risks/infrastructure/item381

3 Structural reforms imply regulatory and institutional improvements to enhance market efficiency (for instance the labor market or goods market), or efforts to stimulate economic growth beyond its potential (Rodrik, 2015). Structural reform policy is very broad and encompasses infrastructure development, tax and subsidy regulations, improving HR quality, wages and employment regulations and bureaucratic reform. 
From the developments above and considering the important role of infrastructure in terms of nurturing economic growth, quantitative analysis regarding the impact of larger government investment in infrastructure is needed to predict the impact on output and welfare. With a simple approach, the impact of larger government investment in infrastructure on economic growth can be observed using the output multiplier of government spending. Nonetheless, that approach contains several inherent weaknesses, including limited time series data, particularly relating to structural policies. In addition, the simple approach is also lack of the micro-behaviour of individual economic agents and limitations in terms of detecting the linkages between macro variables.

This paper aims to quantitatively analyse the impact of structural reforms - specifically an increase in government spending for investment - on output and welfare in Indonesia using a Dynamic Stochastic General Equilibrium (DSGE) model. Using a DSGE model, the behaviour of economic agents and the linkages between economic players are formulated explicitly. In addition, the DSGE model can not only detect the impact on output, but also on welfare. The DSGE model will be developed consisting of five sectors, namely the household sector, corporate sector, monetary sector, fiscal sector and external sector.

This model adds to the existing DSGE models at Bank Indonesia, which, in general, focus more on banking industry and financial sector modelling, to analyze simulations of monetary policy, macroprudential policy and the monetary and macroprudential policy mix. The model will also complement the Growth Diagnostics model used by Bank Indonesia to analyze the most binding constraints to growth and the impact of structural reforms using the Computable General Equilibrium (CGE)-INDOTERM model (Anugrah et al., 2015). The CGE model used in Growth Diagnostics, however, is unable to capture the dynamics of the monetary sector, fiscal sector and external sector. In addition, the CGE model lacks intertemporal linkages in the correlations between variables.

The remainder of the paper is organized as follows. Section 2 provides a short review on the related literature. Section 3 describes the condition of physical infrastructure in Indonesia. Section 4 explains the structure and specification of the model. Section 5 analyzes the results of the model simulations and Section 6 concludes.

\section{LITERATURE REVIEW}

This paper relates to previous studies found in the literature. On one hand, this paper is related to studies analyzing the impact of structural reforms on the economies of other countries, primarily using DSGE models. On the other hand, in terms of modelling at Bank Indonesia, this paper is related to several Bank Indonesia studies using DSGE models. 


\subsection{DSGE Model to Analyze the Impact of Government Spending on the Economy}

One of the models used to analyze the impact of structural reforms in the form of government spending is the DSGE model. Ganelli and Tervala (2015) analyzed the impact of infrastructure development (public investment) on output and welfare using a New Keynesian DSGE model with a two-country structure. In their model, government consumption is included in household utility. Government spending consisted of two types: consumption and investment, while government revenue originated from tax. Accordingly, government investment would accumulate public capital goods. The corporate sector would seek to maximize profit using Calvo Pricing based on the production function and depend on labor input and the capital stock of public infrastructure. The paper of Ganelli and Tervala indicated that government investment increased output in the medium term. Furthermore, efficient government investment is required to ensure a positive welfare multiplier.

Bom and Ligthart (2014) examines the impact of government infrastructure spending on output and welfare in a small open economy OECD member using the Real Business Cycle (RBC) model. Their study sought to answer the question of whether government investment could effectively drive output and ameliorate public welfare if the government is bound by the balanced-budget fiscal rule. In addition, they also look at the dynamic impact of government investment. One characteristic of their model specification is the consumer preference follows a constant elasticity of substitution (CES), where the intratemporal substitution effect of labor supply can be separated from the intertemporal substitution effect. In their model, government investment is financed by the distortionary labor tax and Bom and Ligthart found that government spending on infrastructure had a negative multiplier effect in the short term, which subsequently reversed to become positive in the long term, and a generally positive multiplier effect on welfare. The short-term adverse impact is due to a decline of labor supply as a result of the distortionary labor tax.

In the case of Indonesia, studies regarding the impact of government spending on output have been conducted by Jha et al. (2010) and Tang et al. (2013). Both papers focus on estimating the fiscal multiplier in several Asian countries, including Indonesia. ${ }^{4}$ Jha et al. (2010) used a SVAR model to estimate the effectiveness of fiscal policy in 10 developing countries in Asia. Jha et al. (2010) found that an increase in government spending had a positive impact on GDP in each respective country. Meanwhile, contractive fiscal policy through higher taxes is found to stimulate economic growth in a few countries, including Singapore and Taiwan. Jha et al. (2010) also found that the cumulative fiscal multiplier of government spending in Indonesia is 0.19 , above the fiscal multiplier from lower taxes $(0.18)$.

4 The fiscal multiplier is an indicator often used to gauge the impact of fiscal policy on output. The multiplier concept was first introduced by Kahn (1931) and Keynes (1936). 
Tang at el. (2013) estimate the fiscal multiplier for five ASEAN countries (Indonesia, Malaysia, Philippines, Singapore and Thailand) using a SVAR model. The results show that fiscal policy in the form of lower taxes could have a favorable impact on the five ASEAN members. In Indonesia's case, the fiscal multiplier of lower taxes is 0.43 . In contrast, policy to raise government spending is found to have a negative multiplier effect in Indonesia (-0.34), Singapore (-0.16) and Thailand (-0.27). The main suspect of the negative impact is thought to be imports, which surge due to the small and highly open economies.

Different from the previous two studies on the impact of total government spending on output, this paper examines government spending not as an aggregate but from the perspective of each component, namely spending on investment and spending on consumption. Consequently, the impact of government efforts to increase investment spending can be quantified using the DSGE model developed. In addition, considering the DSGE model is a micro-founded model, the magnitude of impact is not only observed in terms of output but also other macro aggregates (such as inflation and the trade balance) as well as welfare.

\subsection{DSGE Models at Bank Indonesia}

Like many other central banks, Bank Indonesia has developed several DSGE models. This paper adds to the existing range of DSGE models in Bank Indonesia. After the global financial crisis, DSGE modelling at Bank Indonesia focused on the financial sector. Tjahjono and Waluyo (2010) developed a DSGE model to include the financial accelerator (procyclicality effect), aiming to detect the financial accelerator and its impact on the macroeconomy in the case of a shock, capture the linkages between the monetary and macroprudential policies, simulate the impact of rising fuel prices and analyze the policy mix in the face of economic recession and banking crisis. In the event of a monetary shock, the model with a financial accelerator produces a larger macroeconomic impact than the model without a financial accelerator. An increase in the oil price could potentially lower output, raise inflation and depreciate the rupiah. Furthermore, the impact of monetary policy is more pronounced than that of banking policy in the form of risk-weighted assets (RWA). Nonetheless, the policy mix is still required to maintain the Capital Adequacy Ratio (CAR) as well as prevent and mitigate systemic risk.

Harmanta et al. (2012) developed a DSGE model equipped with the banking sector and applying financial frictions in the household sector in the form of collateral constraints. Their model could be used to assist policy mix formulation as implemented by Bank Indonesia. The simulations show that a hike in the BI Rate would raise bank retail interest rates, reduce lending as well as increase risk-free assets and, therefore, ultimately lower GDP and inflation. An increase in the reserve calculated based on the ratio of changes in national income to changes in government spending or tax revenues. 
Requirement is shown not to have a significant impact because of excess liquidity in the Indonesian banking sector. An increase in the loan-to-value (LTV) ratio for household/corporate loans, however, could increase output and inflation.

Harmanta et al. (2013) developed further the previous model by adding financial frictions on the entrepreneur side in the form of a financial accelerator, in addition to frictions on the household side. The simulations showed that a hike in the BI Rate would raise the retail interest rate in the banking industry, reduce lending and increase risk-free assets, thereby lowering inflation and GDP. Banks are also exposed to risks as rising non-performing loans (NPL) erode capital. Raising the LTV ratio for households would spur asset purchases, while elevating output and inflation. Raising the Capital Adequacy Ratio (CAR) would lower the loanto-deposit ratio (LDR), investment and production and, thus, GDP and inflation. The monetary and macroprudential policy mix would create more stable GDP and inflation as well as control consumption and demand for imports.

Harmanta et al. (2014) extended the previous model with an interbank market mechanism as financial frictions on the supply side, while frictions are added to the demand side in the form of collateral constraints and the financial accelerator. The simulations showed that a shock on the interbank market would affect general bank dynamics, particularly bank capital, the Capital Adequacy Ratio (CAR) and loan-to-deposit ratio (LDR). Their model could detect procyclicality and the financial accelerators. Furthermore, the monetary and macroprudential policy mix tended to produce more stable GDP and inflation compared to using just one policy instrument.

\section{INFRASTRUCTURE CONDITION IN INDONESIA AND THE GOVERNMENT'S PLAN TO STRENGTHEN INFRASTRUCTURE}

\subsection{Infrastructure in Indonesia}

The condition of infrastructure in Indonesia has improved over the past few years, as reflected by the infrastructure competitiveness index published by the World Economic Forum (WEF). As shown in Figure 1a, the ranking of Indonesia's infrastructure improved from 92th in 2012 to 60 th in 2016 . The most salient improvements affected the quality of railways and roads as well as ports (Figure 1b). 


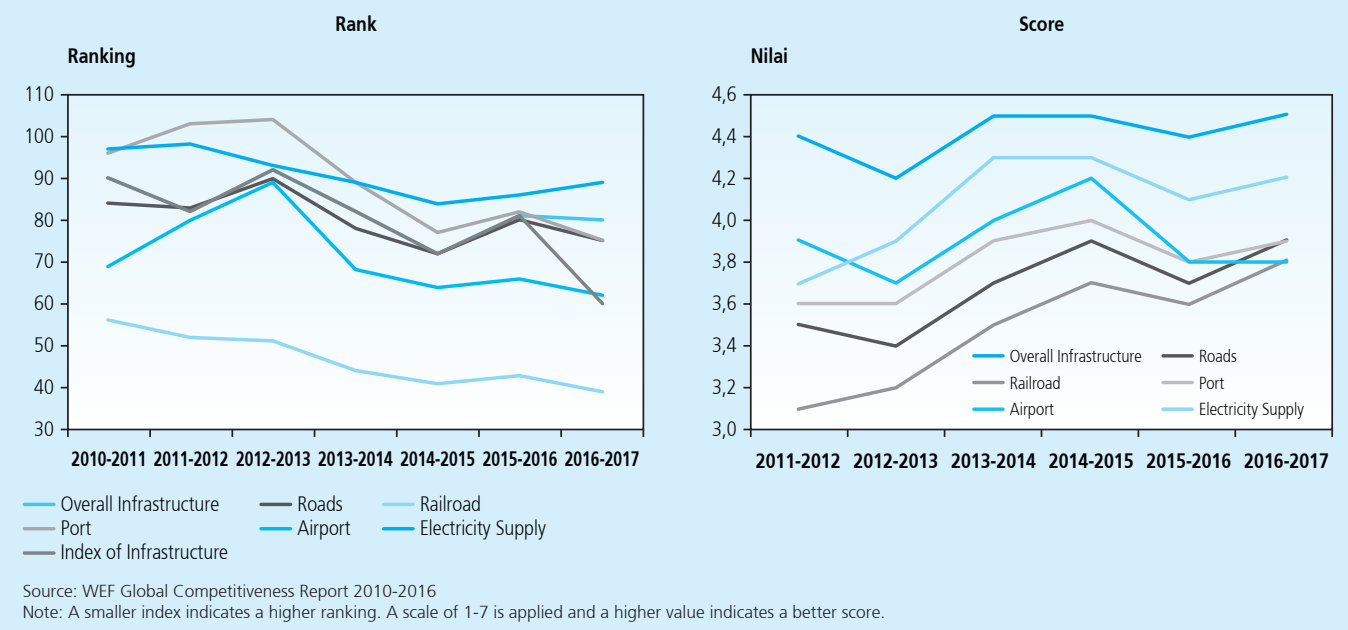

(a)

(b)

Figure 1. Indonesian Infrastructure Index

Despite the recent improvements, several aspects of infrastructure in Indonesia are behind peer countries in the region. Data from The Global Competitiveness Report for 2016-2017, released by the World Economic Forum (WEF), show that the overall score for infrastructure in Indonesia was 3.8 (ranked 80th), which is well below Malaysia and Thailand with respective scores of 5.5 (19th) and 4.0 (72nd) (Figure 2). In more detail, the quality of roads in Indonesia received a score of 3.9 (ranked 75th worldwide), still below Malaysia with a score of 5.5 (20th) and Thailand with 4.4 (60th). On the other hand, the quality of railways in Indonesia received a score of 3.8 (ranked 39th worldwide), which is also still below Malaysia with a score of 5.1 (15th). The quality of ports in Indonesia received a score of 3.9 (75th), below Malaysia with a score of 5.4 (17th) and Thailand with 4.2 (65th). Regarding the quality of airports, Indonesia received a score of 4.5 (62nd), while Malaysia and Thailand received respective scores of 5.7 (20th) and 5.0 (42nd). 


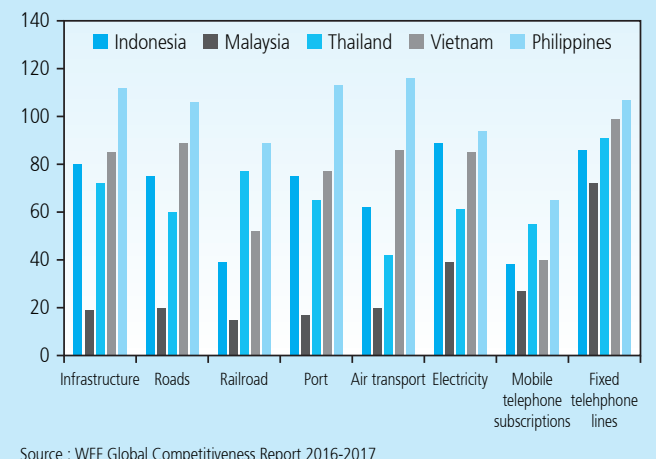

Figure 2.

Infrastructure Index of ASEAN Countries

The WEF report also states that the lack of infrastructure in Indonesia was the third biggest constraint to business development over the past few years, after corruption and inefficient government bureaucracy (Figure 3).

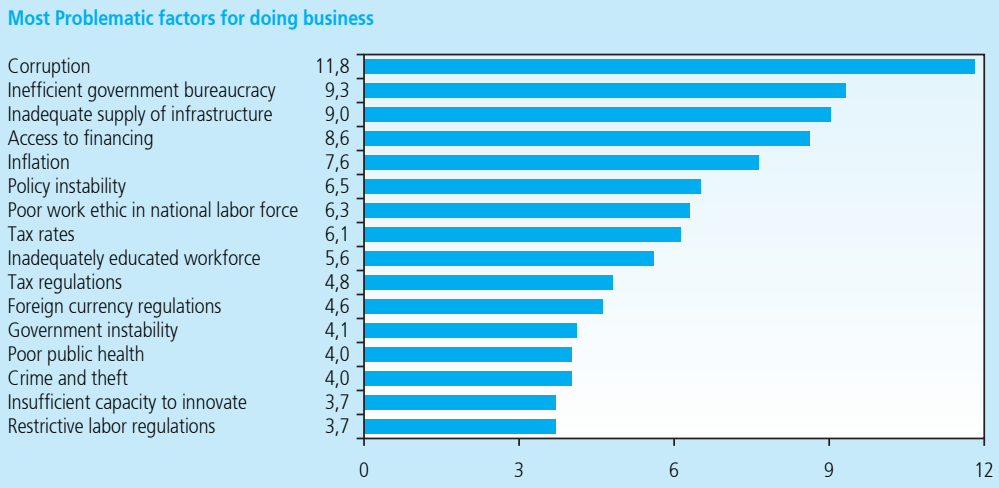

Source: WEF Global Competitiveness Report 2016-2017

Figure 3.

Most Problematic Factors for Doing Business in Indonesia

One element of national infrastructure that has received government attention is interregional connectivity. Infrastructure constraints linked to connectivity, such as inadequate ports and poor quality roads, have pushed up the cost of logistics, which is a fundamental problem often found throughout Indonesia. The provision of such infrastructure would lower the cost of transportation and logistics, thereby enhancing product competitiveness and 
accelerating the pace of the economy. The Logistics Performance Index (LPI), released by the World Bank in 2016, showed that Indonesia placed 63rd out of the 160 countries monitored, with a score of 2.98, down 10 places on the ranking in LPI 2014.

Compared to peer countries in the region, Indonesia remains below Malaysia and Thailand in terms of all LPI aspects, namely customs, infrastructure, international shipping, logistics competencies, tracking and recording as well as timeliness. Indonesia recorded a score of 2.69 for customs, compared to 3.17 in Malaysia and 3.11 in Thailand. For infrastructure, Indonesia received a score of 2.65, while Malaysia and Thailand scored at 3.45 and 3.12, respectively. In terms of international shipping, Indonesia again scored lower than Malaysia and Thailand with scores of 2.90, 3.48 and 3.37 respectively. Concerning logistics competencies, Indonesia received a score of 3.00, compared to 3.34 in Malaysia and 3.14 in Thailand (Figure 4).
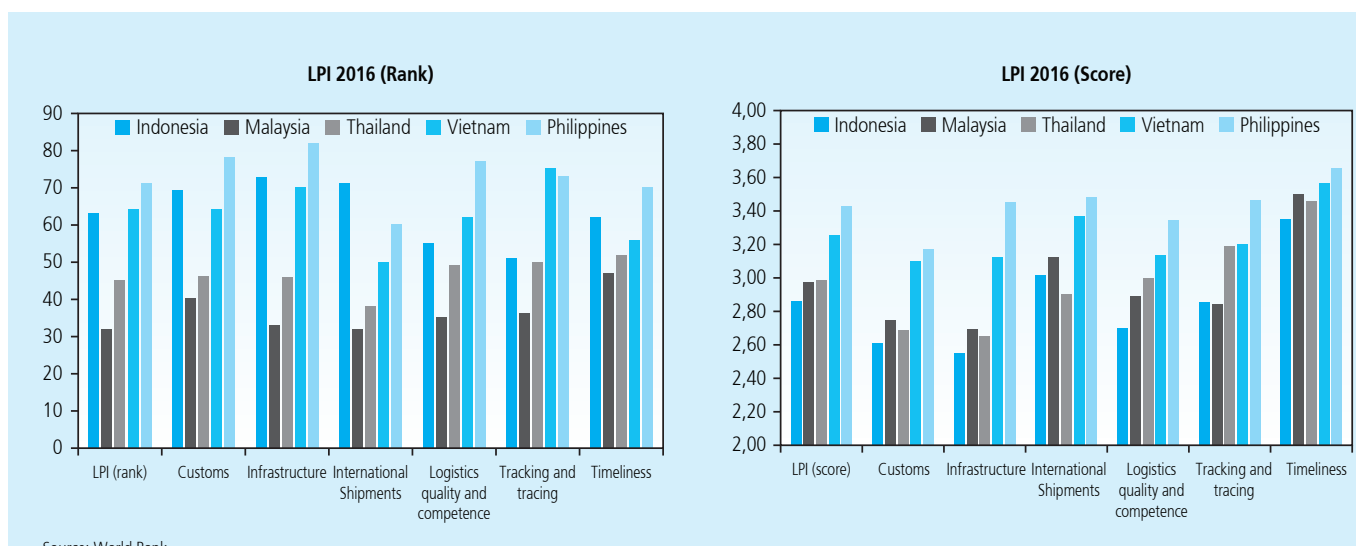

Figure 4.

Comparison of Logistics Performance between ASEAN Countries

\subsection{Government Investment in Infrastructure}

One of the main reasons for the lack of adequate infrastructure in Indonesia is relatively low government investment. The ratio of government investment to GDP in Indonesia from 2006-2014 averaged just 2\%, well below Malaysia and Thailand at 9.9\% and 6.4\% respectively (Figure 5). In 2015, the government increased investment significantly from $2.41 \%$ to $3.23 \%$ of GDP, thereby surpassing government investment in the Philippines at $2.81 \%$ but still trailing Malaysia and Thailand. 


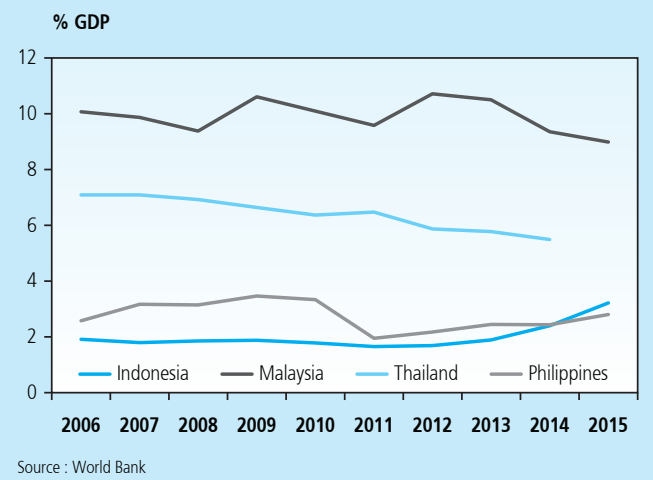

Figure 5. Comparison of Government Investment between ASEAN Countries

In order to achieve higher and sustainable economic growth, the government is committed to improving the quality and quantity of infrastructure. Such commitment is evidenced by the infrastructure development targets to be achieved by 2019, pursuant to the Medium-Term National Development Plan (RPJMN) for 2015-2019 (Table 1).

\begin{tabular}{|c|c|c|}
\hline \multicolumn{3}{|c|}{$\begin{array}{l}\text { Table } 1 . \\
\text { Infrastructure Development Targets in RPJMN (2015-2019) }\end{array}$} \\
\hline Indicator & 2014 Baseline & 2019 Target \\
\hline \multicolumn{3}{|l|}{ Basic infrastructure of energy and electricity } \\
\hline Electrification ratio (\%) & 84.1 & 96.6 \\
\hline Electricity consumption per capita (kWh) & 843 & 1200 \\
\hline Establishment of Floating Storage Regasification Unit (unit) & 2 & 3 \\
\hline Gas pipelines (km) & 11,960 & 17,690 \\
\hline Establishment of gas station for transportation (unit) & 40 & 118 \\
\hline Use of natural gas (household connection) & 102 Thousand & 1 Million \\
\hline Addition of petroleum refineries (unit) & - & 2 \\
\hline \multicolumn{3}{|l|}{ Basic Infrastructure of residential areas } \\
\hline Clean water access & $68.5 \%$ & $100 \%$ \\
\hline Adequate sanitation access & $60.5 \%$ & $100 \%$ \\
\hline Urban slums neighborhood & $37.407 \mathrm{Ha}$ & $0 \mathrm{Ha}$ \\
\hline Housing backlog & 13.5 Million & 6.8 Million \\
\hline \multicolumn{3}{|l|}{ Connectivity } \\
\hline Well-maintained National Roads & $94 \%$ & $100 \%$ \\
\hline Logistic cost (\%GDP) & $23.5 \%$ & $19.2 \%$ \\
\hline Urban public transport market share & $23 \%$ & $32 \%$ \\
\hline
\end{tabular}




\begin{tabular}{|c|c|c|}
\hline \multicolumn{3}{|c|}{$\begin{array}{c}\text { Table } 1 . \\
\text { Infrastructure Development Targets in RPJMN (2015-2019) }\end{array}$} \\
\hline Indicator & 2014 Baseline & 2019 Target \\
\hline Boardband coverage to regencies/ cities & $72 \%$ & $100 \%$ \\
\hline Water Durability & & \\
\hline Standard water infrastructure capacity & $51.4 \mathrm{M} 3 / \mathrm{Sec}$ & $118.6 \mathrm{M} / \mathrm{Sec}$ \\
\hline Water storage capacity per capita & $62.3 \mathrm{M} 3 /$ Capita & 78.36 M3/Capita \\
\hline Dam irrigation coverage & $11 \%$ & $20 \%$ \\
\hline Surface Irrigation Networks & 7,145 Million $\mathrm{Ha}$ & 7,914 Million $\mathrm{Ha}$ \\
\hline Flood control capacity & $5-25$ Years & $10-100$ Years \\
\hline
\end{tabular}

To achieve those targets, the government has already stipulated the infrastructure to be built during from 2015-2019. Accordingly, a total of 225 infrastructure projects have been designated as national strategic government projects. In addition, the government is also developing a $35,000 \mathrm{MW}$ national electricity project that is separate from the other national strategic projects. Of the total, around 46 projects are located in Sumatra, 89 in Java, 24 in Kalimantan as well as 16 in Bali and Nusa Tenggara. There are a further 28 projects located in Sulawesi, 13 in Maluku and Papua and 10 more distributed in various provinces. The national strategic projects are based on Presidential Decree No. 3/2016 concerning the Acceleration of National Strategic Project Implementation, as well as Presidential Instruction No. 1/2016 regarding the Acceleration of National Strategic Project Implementation.

The acceleration of national strategic projects is pursuant to Presidential Decree No. 3/2016, which regulates licensing and non-licensing, government procurement of goods/ services, discretional debottlenecking, spatial planning, land acquisition, government funding and guarantees, as well as the use of domestic apparatus. Data from the Coordinating Ministry of Economic Affairs showed that in June 2016, a total of 86 projects (44\%) had completed ground breaking and entered the construction phase, while the remaining 139 projects were still at the planning phase or set to commence implementation. Furthermore, per June 2016, of the total planned 35,000MW electricity project, as much as 17,800MW had been signed to project contracts.

To expedite infrastructure development, the government introduced fiscal, institutional and regulatory reforms. The institutional reforms included strengthening The Committee for Acceleration of Priority Infrastructure Delivery (KPPIP) and the Presidential Decree on National Strategic Projects. In addition, the government also reclassified the projects to ensure a greater focus on project completion. Of the 225 existing national strategic projects and one electricity program, pursuant to Coordinating Minister of Economic Affairs Decree No. 12/2015, the government has designated 30 priority projects to receive special attention from KPPIP. 
Infrastructure investment, which has become a government priority, is still constrained by a lack of funding. Data from the National Development Planning Agency, as contained in the MediumTerm National Development Plan (RPJMN) for 2015-2019, stipulates the funding requirement for the priority infrastructure projects from 2015-2019 at Rp5,519.4 trillion. The funding requirement consists of government ministry/agency spending and regional transfers (national budget and local government budgets) amounted to Rp2,760.9 trillion or around $50.02 \%$, state-owned enterprises amounted to Rp1,066.2 trillion or $19.32 \%$, and private participation amounted to Rp1,692.3 trillion or 30.66\% (Table 2).

\begin{tabular}{|c|c|c|c|c|c|}
\hline \multicolumn{6}{|c|}{$\begin{array}{l}\text { Table } 2 . \\
\text { Funding Requirement for Infrastructure in RPJMN 2015-2019 }\end{array}$} \\
\hline Sector & $\begin{array}{c}\text { State } \\
\text { Budget } \\
\text { (APBN) }{ }^{1}\end{array}$ & $\begin{array}{c}\text { Regional } \\
\text { Budget } \\
\text { (APBD) }\end{array}$ & SoE (BUMN) $)^{2}$ & Private $^{3}$ & Total \\
\hline Road & 340.0 & 200.0 & 65.0 & 200.0 & 805.0 \\
\hline Railway & 150.0 & - & 11.0 & 122.0 & 283.0 \\
\hline Sea transportation ${ }^{4}$ & 498.0 & - & 238.2 & 163.8 & 900.0 \\
\hline Air transportation & 85.0 & 5.0 & 50.0 & 25.0 & 165.0 \\
\hline Land transportation & 50.0 & - & 10.0 & - & 60.0 \\
\hline City transportation ${ }^{5}$ & 90.0 & 15.0 & 5.0 & 5.0 & 115.0 \\
\hline Electricity ${ }^{6}$ & 100.0 & - & 445.0 & 435.0 & 980.0 \\
\hline Energy (oil and gas) & 3.6 & - & 151.5 & 351.5 & 506.6 \\
\hline $\begin{array}{l}\text { Information and communication } \\
\text { technology }\end{array}$ & 12.5 & 15.3 & 27.0 & 223.0 & 277.8 \\
\hline Water resources & 275.5 & 68.0 & 7.0 & 50.0 & 400.5 \\
\hline Drinking water and sanitation & 227.0 & 198.0 & 44.0 & 30.0 & 499.0 \\
\hline Housing & 384.0 & 44.0 & 12.5 & 87.0 & 527.5 \\
\hline Total Infrastructure & $2,215.6$ & 545.3 & $1,066.2$ & $1,692.3$ & $5,519.4$ \\
\hline Percentage & $40.14 \%$ & $9.88 \%$ & $19.32 \%$ & $30.66 \%$ & $100.00 \%$ \\
\hline $\begin{array}{l}\text { Source: Ministry of National Developmer } \\
\text { 1) Expected state budget support } \\
\text { 2) Expected state-owned enterprise su } \\
\text { 3) Maximum capacity of private finance } \\
\text { 4) Increase due to the addition of sea } \\
\text { 5) Allocated for rail and road-based urt } \\
\text { 6) PT PLN has the capability to finance }\end{array}$ & $\begin{array}{l}\text { nning Notes: } \\
\text { ugh Public-Private } \\
\text { mponent and rout } \\
\text { ansport } \\
250 \mathrm{~T} \text {, the remaini }\end{array}$ & $\begin{array}{l}\text { artnership including } \\
\text { cost } \\
\text { cost requires state }\end{array}$ & business to busine & cheme & \\
\hline
\end{tabular}


In line with government efforts to improve the quality and quantity of infrastructure, the national budget allocation to infrastructure has increased significantly. Based on data from the Ministry of Finance, government spending on infrastructure in 2015 reached Rp290.3 trillion (3.23\% of GDP), up 40.5\% from the previous year. A further increase was observed in 2016, with the budget allocation went up to Rp313.5 trillion. In 2017, Rp346.6 trillion has been earmarked for infrastructure. With the growing infrastructure budget through to 2019, government spending on infrastructure is expected to reach $4.21 \%$ of GDP (Figure 6). As an aggregate for 2015-2019, the government's infrastructure budget is predicted to reach Rp1,796.2 trillion.

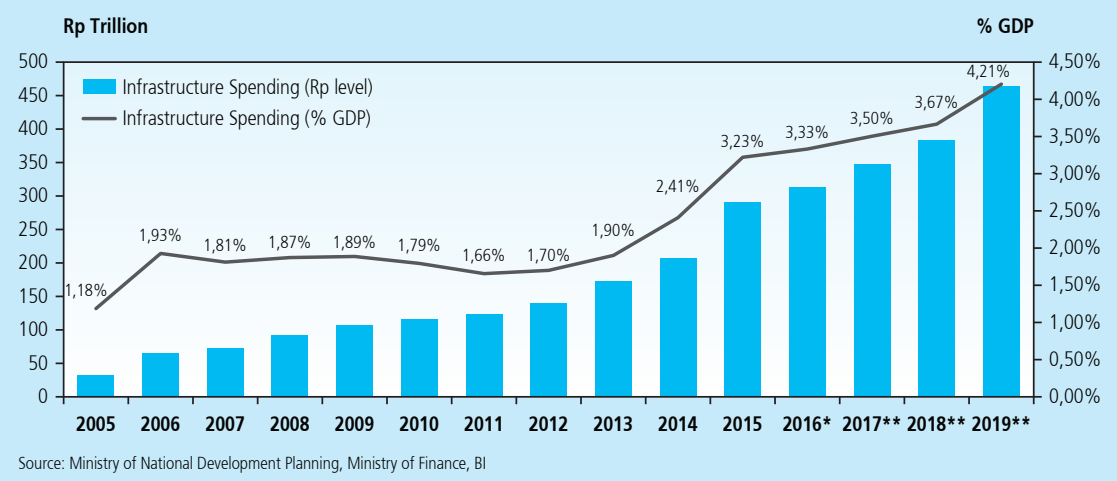

Figure 6.

Goverment Spending on Infrastructure 2015-2019

\section{DSGE MODEL}

The model developed in this paper is based on Ganelli and Tervala (2015), where government consumption and investment are inputted separately into a New Keynesian DSGE Model. The main modification to the model is to assume a small open economy in order to enrich the impact assessment of structural reforms in Indonesia. In general, the model also contains the features of the standard DSGE model based on the model of Gali and Monacelli (2005). The structure of the model is presented in Figure 7. 


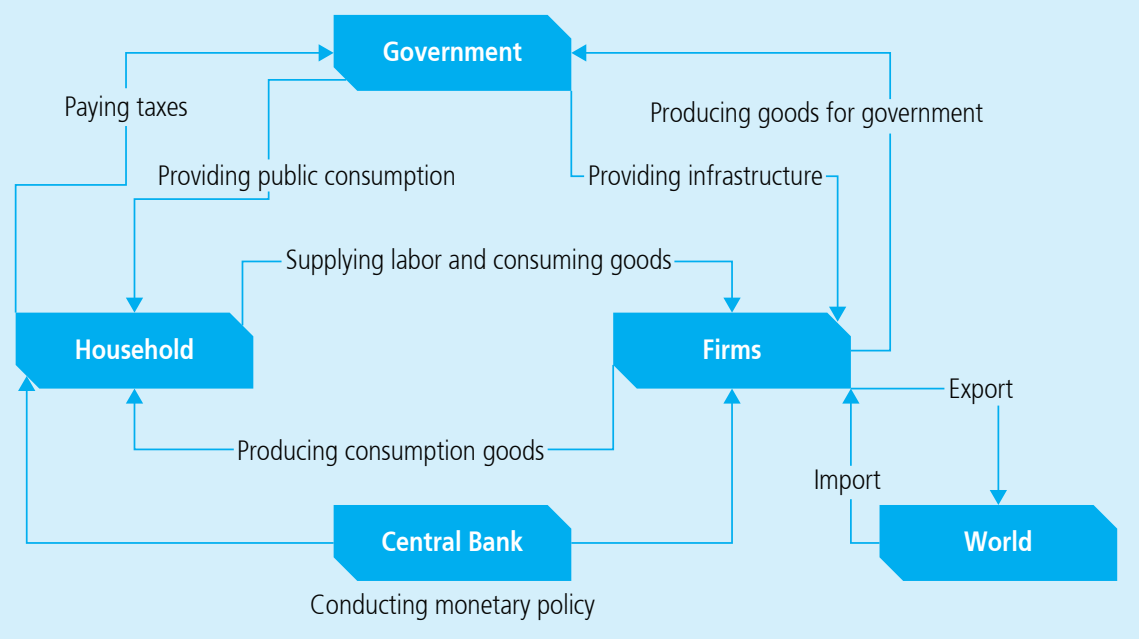

Figure 7.

Structure of the Model

\subsection{Households}

\subsubsection{Household Utility Maximization}

All households are assumed to have the same preferences. Households maximize their utility function based on their choice of consumption level, $C_{t^{\prime}}$ and time spent resting (outside working hours, $\left.N_{t}\right)$, given the public goods, $G_{t}{ }^{c}$, provided by the government.

$$
\max _{\left\{C_{t} N_{t}\right\}} E_{t} \sum_{t=0}^{\infty} \beta^{t}\left[\frac{C_{t}^{1-\sigma}}{1-\sigma}-\frac{\left(N_{t}\right)^{1+\varphi}}{1+\varphi}+v \log G_{t}^{C}\right]
$$

where $\beta$ is discount factor, $\sigma$ is intertemporal elasticity of substitution of household, $\varphi$ is labor supply elasticity, and $v$ is weight of public consumption.

Households receive an income from wages for providing labor to a firm, $W_{t} N_{t^{\prime}}$ income from term deposits, $\left(1+i_{t}\right) D_{t^{\prime}}$ and dividends from their own businesses, $\Pi_{t^{\prime}}$. The income is used to pay taxes, $T_{t^{\prime}}$ and spend on consumption. Therefore, the budget constraints faced by households is the following:

$$
P t C t+Q t+1 D t+1=D t+W t N t+\Pi t-P t T t
$$

where $Q_{t+1}=\frac{1}{1+i_{t}}$ is a stochastic discount factor. In the budget constraints, spending on consumption and taxes are multiplied by prices to form the nominal value. 
Optimizing the objective function (1) with the budget constraint (2) produces the optimal solution (First Order Condition) for consumption, $C_{t^{\prime}}$ and working time, $N_{t^{\prime}}$ as follows:

$$
\begin{gathered}
C_{t}^{\sigma}=Q_{t+1} E_{t}\left\{C_{t+1}^{\sigma} \frac{P_{t+1}}{P_{t}}\right\} \frac{1}{\beta} \\
N_{t}^{\varphi}=\frac{W_{t}}{C_{t}^{\sigma} P_{t}}
\end{gathered}
$$

Households determine their level of consumption at time t, $C_{t^{\prime}}$ by considering the expected spending on consumption in future periods, $C_{t+1^{\prime}}^{\sigma}$ price changes, $\frac{P_{t+1}}{P_{t}}$, and the discount factor. Meanwhile, households choose to work, $N_{t}{ }^{\varphi}$, in line with the wages received, $W_{t^{\prime}}$ to meet the consumption requirement.

\subsubsection{Optimum Consumption Allocation of Households}

Household consumption, $C_{t^{\prime}}$ is a composite index of domestic goods, $C_{H, t^{\prime}}$ and imported goods $C_{F, t}$.

$$
C_{t}=\left\lceil(1-\alpha)^{\frac{1}{\eta}}\left(C_{H, t}\right)^{\frac{\eta-1}{\eta}}+\alpha^{\frac{1}{\eta}}\left(C_{F, t}\right)^{\frac{\eta-1}{\eta}}\right\rceil^{\frac{\eta}{\eta-1}}
$$

where $\alpha$ is the consumption home bias parameter and $\eta$ is elasticity of substitution between domestic and imported goods. The respective consumption of domestic goods, $C_{H, t^{\prime}}$ and imported goods, $C_{F, t^{\prime}}$ constitute aggregate consumption of various types of goods $j$, namely:

$$
\begin{aligned}
& C_{H, t}=\left(\int_{0}^{1} C_{H, t}(j)^{\frac{\varepsilon-1}{\varepsilon}} d j\right)^{\frac{\varepsilon}{\varepsilon-1}} \\
& C_{F, t}=\left(\int_{0}^{1} C_{F, t}(j)^{\frac{\gamma-1}{\gamma}} d j\right)^{\frac{\gamma}{\gamma-1}}
\end{aligned}
$$

where $\varepsilon$ and $\gamma$ are the elasticity of substitution between varieties of domestic and foreign goods respectively.

Households maximize total consumption by determining the consumption allocation for various types of goods, $j$, for each level of spending, $Z_{t}$.

$$
\begin{aligned}
& \max _{\left\{C_{x, t}\right\}}\left(\int_{0}^{1} C_{x, t}(i)^{1-\frac{1}{\vartheta}} d i\right)^{\frac{\vartheta}{\vartheta-1}} \\
& \text { s.t } \int_{0}^{1} P_{x, t}(i) C_{x, t}(i) d i=Z_{t}
\end{aligned}
$$


$x=H, F$, and $\vartheta=\varepsilon, \gamma$. The optimal solution (FOC) for this problem is for households to allocate the consumption of goods, $j$, according to relative prices of other goods and the substitution elasticity between goods, which can be expressed as follows:

$$
C_{x, t}(j)=\left(\frac{P_{x, t}(j)}{P_{t}}\right)^{-\vartheta} C_{t}
$$

Furthermore, households will also maximize their consumption allocation between domestic and international goods. With the same settlement measures as before, the optimal solution in terms of consuming domestic and international goods will be obtained as follows:

$$
\begin{gathered}
C_{H, t}=(1-\alpha)\left(\frac{P_{H, t}}{P_{t}}\right)^{-\eta} C_{t} \\
C_{F, t}=\alpha\left(\frac{P_{F, t}}{P_{t}}\right)^{-\eta} C_{t}
\end{gathered}
$$

where

$$
P_{t}=\left[(1-\alpha)\left(P_{H, t}\right)^{1-\eta}+\alpha\left(P_{F, t}\right)^{1-\eta}\right]^{\frac{1}{\eta-1}}
$$

is the consumption price index.

\subsubsection{Relationship between Domestic and International Prices and Consumption}

A price comparison between domestic and international goods (terms of trade) can be expressed as $S_{t}=\frac{P_{F, t}}{P_{H, t}}$, or in log-linear form as $s_{t}=p_{F, t}-p_{H, t}$. Meanwhile, the log-linear form of the consumer price index equation (5) in a steady state condition produced $p_{t}=(1-\alpha) p_{H, t}+\alpha p_{F, t^{\prime}}$ therefore $p_{t}=p_{H, t}+\alpha s_{t}$. Thus, a change in the Consumer Price Index (CPI) is determined by a change of domestic prices and a change in the terms of trade (ToT).

$$
\pi t=\pi H, t-\alpha(s t-s t-1)
$$

International commodity prices in the domestic currency $\left(p_{F, t}\right)$ are the same as global prices in a foreign currency $\left(p_{t}^{*}\right)$ multiplied by the nominal exchange rate $p_{F, t}=e_{t}+p_{t}{ }^{*}$. Therefore, the terms of trade can also be formulated as follows:

$$
s_{t}=e_{t}+p_{t}^{*}-p_{H . t}
$$


Meanwhile, the real exchange rate can be defined as a change in international prices in the domestic currency divided by domestic prices (Consumer Price Index):

$$
q t=e t+p t *-p t
$$

Thus, the relationship between the real exchange rate and the terms of trade can be defined as follows:

$$
q t=(1-\alpha) s t
$$

Furthermore, assuming linearity, changes in the real exchange rate and global growth to meet domestic demand will determine the magnitude of change in domestic consumption:

$$
\begin{gathered}
c_{t}=c_{t}^{*}+\frac{1}{\sigma} q_{t} \\
c_{t}=c_{t}^{*}+\frac{(1-\alpha)}{\sigma} s_{t}
\end{gathered}
$$

\subsubsection{Market Clearing between Consumption and Production}

In equilibrium, companies produce goods at the same amount with government spending and household consumption such that:

$$
Y_{t}=G_{t}^{C}+G_{t}^{I}+(1-\alpha)\left(\frac{P_{H, t}}{P_{t}}\right)^{-\eta}\left(C_{t}\right)+\alpha \int_{0}^{1}\left(\frac{P_{H, t}}{\varepsilon_{i, t} P_{F, t}^{i}}\right)^{-\gamma}\left(\frac{P_{F, t}^{i}}{P_{t}^{i}}\right)^{-\eta} C_{t}^{i} d i
$$

Using the terms of trade and exchange rate equations, the equation above can be expressed as:

$$
Y_{t}=G_{t}^{C}+G_{t}^{I}+\left(\mathcal{S}_{t}^{-\alpha}\right)^{-\eta}\left[(1-\alpha) C_{t}+\alpha C_{t} \int_{0}^{1}\left(\mathcal{S}_{t}^{i} \mathcal{S}_{i, t}\right)^{\gamma-\eta} \mathcal{Q}_{i, t}^{\eta-\frac{1}{\sigma}} d i\right]
$$

\subsection{Firms}

\subsubsection{Minimizing Production Costs}

Firms are assumed to have factors of production consisting of labor and public infrastructure provided by the Government. A production function is also assumed to be linear with respect to technological progress. Each firm produces various different products $j$ :

$$
Y t(j)=A t(K t G) \Phi N t(j)
$$

where $\Phi$ is output elasticity to public infrastructure. Parameter $\Phi$ is assumed to have a positive value, implying that the production function has an increasing returns with respect to public infrastructure. The problem faced by firms in finding the real marginal cost is to minimize the real total cost given certain level of production. Firms choose number of labors to minimize the real total cost as follows: 


$$
\min _{\left\{N_{t}\right\}} T C(i)=\frac{W_{t} N_{t}(i)}{P_{t}}
$$

Optimization of the objective function (7) with the constraint (6) produces the optimum function of the marginal cost $M C_{t}$ as follows:

$$
M C_{t}(i)=\frac{W_{t}}{P_{t} A_{t}\left(K_{t}^{G}\right)^{\Phi}}
$$

Therefore, the marginal cost is found to be equivalent to spending on real wages $\frac{W_{t}}{P_{t}}$ divided by the marginal product of labor $A_{t}\left(K_{t}^{G}\right)^{\Phi}$.

\subsubsection{Maximizing Profit and Price Setting}

In this model, each firm is assumed to produce various different products $j$, thus giving the company bargaining power to change the prices of its products $P_{t}(j)$. A portion of firms are assumed to set prices flexibly with a price index $P_{t^{\prime}}$ and some firms strive to seek optimal prices $P_{t}^{*}$. With the presence of price rigidity, the process of setting optimal prices follows the framework introduced by Calvo (1983).

$$
\begin{gathered}
\max _{\left\{P_{t}^{*}\right\}} \sum^{\infty} k=0 \theta^{k} E_{t}\left[Q_{t, t+k}\left(P_{t}^{*} Y_{t+k \mid t}-P_{t+k} M C_{t+k \mid t} Y_{t+k \mid t}\right)\right] \\
\cdot \quad{ }_{t+k \mid t} \quad \frac{P_{t}^{*}}{P_{t+k}}-\varepsilon{ }^{-\varepsilon} t+k \\
Y_{t+k \mid t}=\left(\frac{P_{t}^{*}}{P_{t+k}}\right)^{-\varepsilon}\left(C_{t+k}+G_{t+k}^{C}+G_{t+k}^{I}\right)
\end{gathered}
$$

The optimal solution of the objective function (9) with the constraint of equation (10) produces the following equation:

$$
P_{t}^{*}=\frac{\varepsilon}{(\varepsilon-1)} \frac{\sum_{k=0}^{\infty} \theta^{k} E_{t}\left[\beta^{k} C_{t+k}^{-\sigma} M C_{t+k} P_{t+k}^{\varepsilon}\left(C_{t+k}+G_{t+k}^{C}+G_{t+k}^{I}\right)\right]}{\sum_{k=0}^{\infty} \theta^{k} E_{t}\left[\beta^{k} C_{t+k}^{-\sigma} P_{t+k}^{\varepsilon-1}\left(C_{t+k}+G_{t+k}^{C}+G_{t+k}^{I}\right)\right]}
$$

The value of $\frac{\varepsilon}{(\varepsilon-1)}$ is called the price mark-up and determined by the elasticity of substitution between domestic products $\varepsilon$.

Each company can optimize or adjust prices with a probability of $1-\theta$ (independent) in each period, thus $\theta<1$ can be interpreted as the price rigidity index. Therefore, the aggregate price $P_{t}$ is as follows:

$$
P_{t}^{1-\varepsilon}=\theta P_{t-1}^{1-\varepsilon}+(1-\theta)\left(P_{t}^{*}\right)^{1-\varepsilon}
$$


By denoting that inflation $\Pi_{t}=\frac{P_{t}}{P_{t-1}}$, then equation (11) can be expressed in the final log-linear form:

$$
\pi_{t}=\frac{(1-\theta)(1-\beta \theta) \widehat{m c}_{t}}{\theta}+\beta E_{t}\left\{\pi_{t+1}\right\}
$$

Equation (12) shows that a change in the optimal price at time $t\left(\pi_{t}\right)$ is the weighted average of the marginal cost in the current period and future price changes. In addition, equation (8) also shows that an increase in the stock of public infrastructure would lower the optimal price.

\subsection{Fiscal and Monetary Policy}

\subsubsection{Fiscal Policy}

The government receives revenue from taxes, which is then used for consumption and investment.

$$
P t T t=G t I+G t C
$$

For simplicity, taxes, $T_{t^{\prime}}$ are non-distortionary. If the government expenditure financed by taxes is distortionary, the impact of expansionary fiscal policy would be less pronounced and, thus, affect the impact on welfare.

Government spending on consumption and investment is modelled using the $A R(1)$ dynamics:

$$
\begin{aligned}
& \hat{g} t C=\rho C \hat{g} t C+\varepsilon t C \\
& \hat{g} t I=\rho I \hat{g} t I+\varepsilon t I
\end{aligned}
$$

Parameters $\rho^{C}$ and $\rho^{I}$ represent the persistence of government consumption and investment shocks. Meanwhile, $\varepsilon_{t}^{C}$ and $\varepsilon_{t}^{I}$ represent i.i.d shocks on government spending with a normal distribution and standard deviation $\sigma_{g}$.

Like Ganelli and Tervala (2015), private capital is omitted from the model, thus providing greater focus on the impact of government investment spending. The stock of public infrastructure is modelled using the following equation:

$$
K_{t+1}^{G}=(1-\lambda) K_{t}^{G}+G_{t}^{l}
$$

The stock of public infrastructure depreciates at $\lambda$ and expands in line with government investment spending. 


\subsubsection{Monetary Policy}

Setting the policy rate $\left(i_{t}\right)$ by the central bank is modelled in the form of a log-linear Taylor rule equation, as introduced by Clarida et al. (2001), as follows:

$$
\hat{\imath}_{t}=\rho_{i} \hat{\imath}_{t-1}+\left(1-\rho_{i}\right)\left(\phi_{\pi} \pi_{t}+\phi_{y} \hat{y}_{t}\right)+\varepsilon_{i}
$$

Parameter $\rho_{i}$ is interest rate smoothing, while $\phi_{\pi}$ and $\phi_{y}$ are the weights of inflation and output stabilization. $\varepsilon_{i}$ is the i.i.d shock on monetary policy.

\subsection{Trade Balance}

The trade balance, represented by $n x_{t^{\prime}}$ illustrates net exports from domestic production as a ratio of the steady state output $Y$. Thus,

$$
n x_{t}=\frac{1}{\bar{Y}}\left(Y_{t}-\frac{P_{t}}{P_{H, t}} C_{t}-G_{t}^{I}-G_{t}^{C}\right)
$$

The log-linearisation of equation (14) can be expressed as follows:

$$
n x_{t}=\bar{Y} \widehat{y}_{t}-\bar{C} \widehat{c}_{t}-\alpha \bar{C} \hat{s}_{t}-\widehat{g_{t}^{I}}-\widehat{g_{t}^{c}}
$$

Equation (15) shows that an increase in government spending on consumption or investment would directly affect the trade balance, which must be offset by the difference between the increase in domestic output and government spending.

\subsection{Measuring the Output Multiplier and Welfare Multiplier of Government Spending}

Following Ganelli and Tervala (2015), we look at the output multiplier of government spending by using the cumulative multiplier (CM), which is calculated using the cumulative change in output divided by the cumulative change in government spending for a given period as follows:

$$
\begin{aligned}
& C M=\frac{\sum_{t=0}^{h} \hat{y}_{t}}{\sum_{t=0}^{h} \hat{g}_{t}^{x}} \\
& x=C, I .
\end{aligned}
$$


In addition, the output multiplier can also be measured based on the net present value of fiscal multiplier (NPVFM), which is calculated as a ratio of the net present value of the change in output to the net present value of the change in government spending for a given period.

$$
N P V M=\frac{\sum_{t=0}^{h} \beta^{t} \hat{y}_{t}}{\sum_{t=0}^{h} \beta^{t} \hat{g}_{t}^{x}}
$$

where $x=C, I$. In this paper, we set number of periods at 2,000 quarters, following Ganelli and Tervala (2015).

To measure the impact of government spending on welfare, the net present value of the impact of fiscal expansion $\left(\tau_{t}\right)$ on welfare is measured as the part of consumption households are willing to release due to fiscal expansion. The value of $\tau_{t}$ is calculated as follows. Based on the household utility function, the net present value of household welfare without fiscal expansion is as follows:

$$
U_{t}^{W F E}=\sum_{t=0}^{\infty} \beta^{t}\left[\frac{C_{t}^{1-\sigma}}{1-\sigma}-\frac{\left(N_{t}\right)^{1+\varphi}}{1+\varphi}+v \log G_{t}^{C}\right]
$$

The net present value of household welfare without fiscal expansion is as follows:

$$
U_{t}^{F E}=\sum_{t=0}^{\infty} \beta^{t}\left[\frac{\left((1+\tau) C_{t}\right)^{1-\sigma}}{1-\sigma}-\frac{\left(N_{t}\right)^{1+\varphi}}{1+\varphi}+v \log G_{t}^{C}\right]
$$

From equations (3.16) and (3.17), the net present value of the impact of fiscal expansion on welfare can be solved as follows:

$$
\tau \approx 100 \times\left\lceil(1-\beta)\left(\hat{C}_{t}-\frac{(\bar{N})^{1+\varphi}}{\bar{C}^{1-\sigma}} \widehat{N}_{t}+\frac{v}{\bar{C}^{1-\sigma}} \widehat{G}_{t}^{C}\right)\right]
$$

Therefore, the welfare multiplier impact is obtained based on the cumulative change in utility (multiplied by the discount factor) and divided by the cumulative government spending.

$$
M_{U} \approx \frac{100 \times(1-\beta) \sum_{t=0}^{\infty} \beta^{t}\left[\hat{C}_{t}-\frac{(\bar{N})^{1+\varphi}}{\bar{C}^{1-\sigma}} \widehat{N}_{t}+\frac{v}{\bar{C}^{1-\sigma}} \widehat{G}_{t}^{C}\right]}{\sum_{t=0}^{h} \beta^{t} \widehat{g}_{t}^{x}}
$$




\subsection{Optimal Solution of the Model}

Optimal solution to the model, based on household, corporate, central bank, government and external conditions, as described above, can be summarised in Table 3:

\begin{tabular}{|c|c|c|}
\hline \multicolumn{3}{|c|}{$\begin{array}{c}\text { Table } 3 . \\
\text { Optimal Solution and Log-linearisation }\end{array}$} \\
\hline No & Optimal Solution (First Order Condition) & Log-linear \\
\hline 1 & $\begin{array}{l}\text { Euler Equation: } \\
c_{t}=E_{t}\left\{c_{t+1}\right\}-\frac{1}{\sigma}\left(i_{t}-E_{t}\left\{\pi_{H, t+1}\right\}-\rho\right)\end{array}$ & $\hat{c}_{t}=E_{t}\left\{\hat{c}_{t+1}\right\}-\frac{1}{\sigma}\left(i_{t}-E_{t}\left\{\pi_{H, t+1}\right\}\right)$ \\
\hline 2 & $\begin{array}{l}\text { Philips Curve: } \\
\qquad \frac{P_{t}^{*}}{P_{t}}=\left(\frac{\varepsilon}{(\varepsilon-1)} \frac{\Psi_{t}^{1}}{\Psi_{t}^{2}}\right) \\
\Psi_{t}^{1}=\sum_{k=0}^{\infty} \theta^{k} E_{t}\left[\beta^{k} C_{t+k}^{-\sigma} M C_{t+k}\left(\frac{P_{t+k}}{P_{t}}\right)^{\varepsilon}\left(C_{t+k}+G_{t+k}^{C}+G_{t+k}^{I}\right)\right] \\
\Psi_{t}^{2}=\sum_{k=0}^{\infty} \theta^{k} E_{t}\left[\beta^{k} C_{t+k}^{-\sigma}\left(\frac{P_{t+k}}{P_{t}}\right)^{\varepsilon-1}\left(C_{t+k}+G_{t+k}^{C}+G_{t+k}^{I}\right)\right]\end{array}$ & $\begin{aligned} \pi_{H, t} & =\beta E_{t}\left(\pi_{H, t+1}\right)+\kappa \widehat{m c}_{t} \\
\kappa & =\frac{(1-\theta)(1-\beta \theta)}{\theta}\end{aligned}$ \\
\hline 3 & $\begin{array}{l}\text { Marginal cost: } \\
M C_{t}(i)=\frac{W_{t}}{P_{t} A_{t}\left(K_{t}^{G}\right)^{\Phi}}\end{array}$ & $\widehat{m c}_{t}=\sigma \hat{c}_{t}+\varphi \hat{n}_{t}-\hat{a}_{t}-\Phi \hat{k}_{t}^{g}$ \\
\hline 4 & $\begin{array}{l}\text { Consumption: } \\
\left(1-c_{t}=c_{t}^{*}+\frac{}{\sigma} s_{t} \alpha\right)\end{array}$ & $c_{t}=c_{t}^{*}+\frac{(1-\alpha)}{\sigma} s_{t}$ \\
\hline 5 & $\begin{array}{l}\text { Inflation: } \\
\pi t=\pi H, t+\alpha(s t-s t-1)\end{array}$ & $\pi t=\pi H, t+\alpha(s t-s t-1)$ \\
\hline 6 & $\begin{array}{l}\text { Terms of trade: } \\
s t=s t-1+(e t-e t-1)+\pi t *+\pi H, t\end{array}$ & $s_{t}=s_{t-1}+\left(e_{t}-e_{t-1}\right)+\pi_{t}^{*}+\pi_{H, t}$ \\
\hline 7 & $\begin{array}{l}\text { Taylor rule: } \\
\hat{\imath}_{t}=\rho_{i} \hat{\imath}_{t-1}+\left(1-\rho_{i}\right)\left(\phi_{\pi} \pi_{t}+\phi_{\pi} y_{t}\right)+\varepsilon_{i}\end{array}$ & $\hat{\imath}_{t}=\rho_{i} \hat{\imath}_{t-1}+\left(1-\rho_{i}\right)\left(\phi_{\pi} \pi_{t}+\phi_{\pi} y_{t}\right)+\varepsilon_{i}$ \\
\hline 8 & $\begin{array}{l}\text { Market Clearing: } \\
\begin{aligned} Y_{t}=G_{t}^{C}+G_{t}^{I}+ & \left(\mathcal{S}_{t}^{-\alpha}\right)^{-\eta}\left[(1-\alpha) C_{t}\right. \\
& \left.+\alpha C_{t} \int_{0}^{1}\left(\mathcal{S}_{t}^{i} \mathcal{S}_{i, t}\right)^{\gamma-\eta} Q_{i, t}^{\eta-\frac{1}{\sigma}} d i\right]\end{aligned}\end{array}$ & $\begin{aligned} \widehat{y_{t}}=\frac{1}{\bar{Y}}\left(\overline{G_{t}^{C}} \widehat{g_{t}^{C}}\right. & +\overline{G_{t}^{I}} \widehat{g_{t}^{I}}+\bar{C} \widehat{c_{t}} \\
& +\bar{C}\left(\alpha \gamma+\alpha \eta-\eta \alpha^{2}-\frac{\alpha}{\sigma}\right. \\
& \left.\left.+\frac{\alpha^{2}}{\sigma}\right) \widehat{s_{t}}\right)\end{aligned}$ \\
\hline 9 & $\begin{array}{l}\text { Capital Law of Motion: } \\
K t G+1=(1-\lambda) K t G+G t I\end{array}$ & $\hat{k}_{t}^{G}=(1-\lambda) \hat{k}_{t-1}^{G}+\lambda \hat{g}_{t-1}^{I}$ \\
\hline 10 & $\begin{array}{l}\text { Employment: } \\
Y t(j)=A t(K t G) \Phi N t(j)\end{array}$ & $\hat{y} t=\hat{a} t+\Phi k t g+\hat{n} t$ \\
\hline 11 & $\begin{array}{l}\text { Trade Balance: } \\
n x_{t}=\frac{1}{\bar{Y}}\left(Y_{t}-\frac{P_{t}}{P_{H, t}} C_{t}-G_{t}^{I}-G_{t}^{C}\right)\end{array}$ & $n x_{t}=\bar{Y} \hat{y}_{t}-\bar{C} \hat{c}_{t}-\alpha \bar{C} \hat{s}_{t}$ \\
\hline 12 & $\begin{array}{l}\text { Inflation: } \\
\pi t=p t-p t-1 \\
\pi H, t=p H, t-p H, t-1 \pi t *=0\end{array}$ & $\begin{array}{l}\pi t=p t-p t-1 \\
\pi H, t=p H, t-p H, t-1 \pi t *=0\end{array}$ \\
\hline
\end{tabular}




\begin{tabular}{|c|c|c|}
\hline \multicolumn{3}{|c|}{$\begin{array}{c}\text { Table } 3 . \\
\text { Optimal Solution and Log-linearisation }\end{array}$} \\
\hline No & Optimal Solution (First Order Condition) & Log-linear \\
\hline 13 & $\begin{array}{l}\text { Technology Shock: } \\
\text { at }=\text { paat }-1+\varepsilon t a\end{array}$ & $a t=\rho a a t-1+\varepsilon t a$ \\
\hline 14 & $\begin{array}{l}\text { Government Investment Shock: } \\
\hat{g}_{t}^{I}=\rho^{I} \hat{g}_{t}^{I}+\varepsilon_{t}^{I}\end{array}$ & $\hat{g}_{t}^{I}=\rho^{I} \hat{g}_{t}^{I}+\varepsilon_{t}^{I}$ \\
\hline 15 & $\begin{array}{l}\text { Government Investment Shock: } \\
\hat{g}_{t}^{C}=\rho^{C} \widehat{g}_{t}^{C}+\varepsilon_{t}^{C}\end{array}$ & $\hat{g}_{t}^{C}=\rho^{C} \hat{g}_{t}^{C}+\varepsilon_{t}^{C}$ \\
\hline
\end{tabular}

\subsection{Steady State Value}

In this paper, the steady state of working hours $N$ is assumed at $1 / 3$, meaning that the labor force spends one-third of its time at work. This value is consistent with Colley (1995). Meanwhile, the steady state of public capital stock ${ }^{-\bar{K} G}$ is normalised to 1 , thus, based on the production function (6), the steady state of output is given by $Y=N$. Furthermore, based on the market clearing equation, the steady state of consumption is $\bar{C}=\bar{Y}-\overline{G_{t}^{C}}-\overline{G_{t}^{I}}$. Based on the capital depreciation equation, the steady state value of government intervention is the same as the rate of depreciation ${ }_{t}^{-G I}=\lambda$.

\subsection{Parameterization}

The parameter values used in the model are determined through a calibration and estimation process. The discount factor $\beta$ is set at 0.99 . The model is interpreted as a quarterly model, and therefore the assumption of $\beta=0.99$ is equivalent to an annualized interest rate of $4 \%$. The elasticity of substitution between domestic and international goods $(\eta)$ is assumed at 3.5, which is consistent with the findings of Obstfeld and Rogoff (1998). Meanwhile, the elasticity of substitution between international goods $\gamma$ is assumed equals to 1, in line with Gali and Monacelli (2005). The elasticity of substitution of labor supply as $\varphi$ is assumed at 1.97 , the same as $\operatorname{Sin}$ (2016) and not far different from Ganelli and Tervala (2015). The wealth effect of labor supply $\sigma$ is assumed equals to 2 .

The value of the Calvo parameter $\theta=0.5$ is assumed at 0.5 , which is the value often used in numerous New Keynesian models and the same as Tjahjono et al. (2009) for the Bank Indonesia Structural Macromodel (BISMA). This assumption leads to a lag of the prices adjustment in two periods (six months). The value of the home bias parameter $(1-\alpha)$ is obtained using the average ratio of imports to GDP from 2005-2015, namely $\alpha=0.2$. Interest rate smoothing $\rho_{i}$ is assumed to have a value of 0.75 , while the respective weights of inflation and output are $\phi_{\pi}$ $=1.9$ and $\phi_{y}=0.25$. The Taylor rule parameters are the same as that estimated by Harmanta et al. (2012). 
Fiscal policy is assumed to have an investment and consumption shock persistence of $\rho^{I}=\rho^{C}=0.75$, respectively, mirroring the findings of Iwata (2013). Meanwhile, the share of government consumption relative to domestic consumption $v$ is assumed at 0.15 , in line with the average value for Indonesia during the period from 2011-2015. Public infrastructure is assumed to depreciate each quarter at the rate of $\lambda=0.025$, which is the same rate of depreciation as that used in the model of Bom and Ligthart (2014). The output elasticity of public infrastructure stock, $\phi_{k^{\prime}}$ is a key parameter in this paper, with $\phi_{k}=0.24$, in line the findings of Aschauer (2000) for the case of low and middle income countries. A summary of the model parameters is presented in Table 4.

\begin{tabular}{|c|c|c|}
\hline \multicolumn{3}{|r|}{$\begin{array}{c}\text { Table } 4 . \\
\text { Calibrated Value of Parameters }\end{array}$} \\
\hline Parameter & Baseline value & Description \\
\hline$\beta$ & 0.99 & Discount factor \\
\hline$\eta$ & 3.5 & Elasticity of substitution between domestic and imported goods \\
\hline$\gamma$ & 1 & Elasticity of substitution between varieties of foreign goods \\
\hline$\varphi$ & 1.97 & Frisch elasticity of labor supply \\
\hline$\sigma$ & 2 & Intertemporal elasticity of substitution of household \\
\hline$\theta$ & 0.5 & Calvo Parameter \\
\hline$\alpha$ & 0.2 & Home bias parameter \\
\hline$\rho_{i}$ & 0.75 & Interest rate smoothing \\
\hline$\phi_{\pi}$ & 1.9 & Taylor rule coefficient for inflation \\
\hline$\phi_{y}$ & 0.25 & Taylor rule coefficient for output \\
\hline$\rho I$ & 0.75 & Persistency of public investment shock \\
\hline$\rho_{c}$ & 0.75 & Persistency of public consumption shock \\
\hline$v$ & 0.15 & Weight of public consumption \\
\hline$\lambda$ & 0.025 & Depreciation rate of public infrastructure \\
\hline$\phi_{k}$ & 0.24 & Output elasticity of public infrastructure \\
\hline
\end{tabular}

The results of parameter calibration are used as the priors for the estimations using Bayesian approach, as explained in Quintana (2012). In this paper, the estimated parameters are $\sigma, \varphi, \gamma, \theta$ and $\eta$. More details, the prior distribution, distribution type and posterior distribution of the parameter estimations are presented in Table 5. 


\begin{tabular}{|c|c|c|c|c|c|}
\hline \multicolumn{6}{|c|}{$\begin{array}{l}\text { Table } 5 . \\
\text { Estimated Value of Parameters }\end{array}$} \\
\hline \multirow[t]{2}{*}{ Parameter } & \multirow[t]{2}{*}{ Description } & \multirow[t]{2}{*}{ Distribution } & \multicolumn{2}{|c|}{ Prior distribution } & \multirow{2}{*}{$\begin{array}{l}\text { Posterior } \\
\text { distribution }\end{array}$} \\
\hline & & & Mean & Std. Dev. & \\
\hline$\theta$ & Calvo parameter & Beta & 0.67 & 0.1 & 0.51 \\
\hline$\sigma$ & $\begin{array}{l}\text { Intertemporal elasticity of } \\
\text { substitution of household }\end{array}$ & Gamma & 2.00 & 0.1 & 2.70 \\
\hline$\varphi$ & Frisch elasticity of labor supply & Gamma & 1.97 & 0.1 & 2.67 \\
\hline$\gamma$ & $\begin{array}{l}\text { Elasticity of substitution between } \\
\text { varieties of foreign goods }\end{array}$ & Gamma & 1.00 & 0.2 & 2.24 \\
\hline$\eta$ & $\begin{array}{l}\text { Elasticity of substitution between } \\
\text { domestic and imported goods }\end{array}$ & Gamma & 3.50 & 0.8 & 1.75 \\
\hline
\end{tabular}

\section{Simulation Results}

This section describes the dynamics of the impulse functions. The discussion focuses on the simulations of fiscal policy, that is, government consumption and government investment shocks. In line with the design of the model, in addition to the impact of fiscal policy on macroeconomic aggregates, the impact on household welfare is also measured. Figure 8 shows the simulation results of fiscal expansion, where the solid line indicates the impact of the government consumption shock and the dashed line illustrates the impact of the government investment shock. In general, the shock produces deviation from the steady state of each respective variable, excluding the trade balance, which is represented by deviation from the steady state of output, and inflation is in percentage change from the previous year.

\subsection{Government Consumption}

In the short run, a $1 \%$ increase in government consumption would potentially results in a $0.04 \%$ higher economic growth above the baseline without policy (Figure 9), driven by an increase in aggregate demand, the wealth effect and working hours. The government would raise taxes to offset the increase in consumption, while the labor force would be offset by an increase in working hours to earn higher wages. Although households reduce their consumption, the aggregate impact of an increase in government consumption remained positive. A cumulative increase in government consumption would raise economic growth by $0.03 \%$ (Table 6).

The trade surplus would initially declines, prompted by an increase in imports to meet government consumption. Thereafter, however, the decrease in household consumption due to raised taxes and an improvement in the terms of trade in the medium-long term, would improve the trade balance. The hump-shaped distribution of the trade balance is in line with Iwata's (2013) study. 

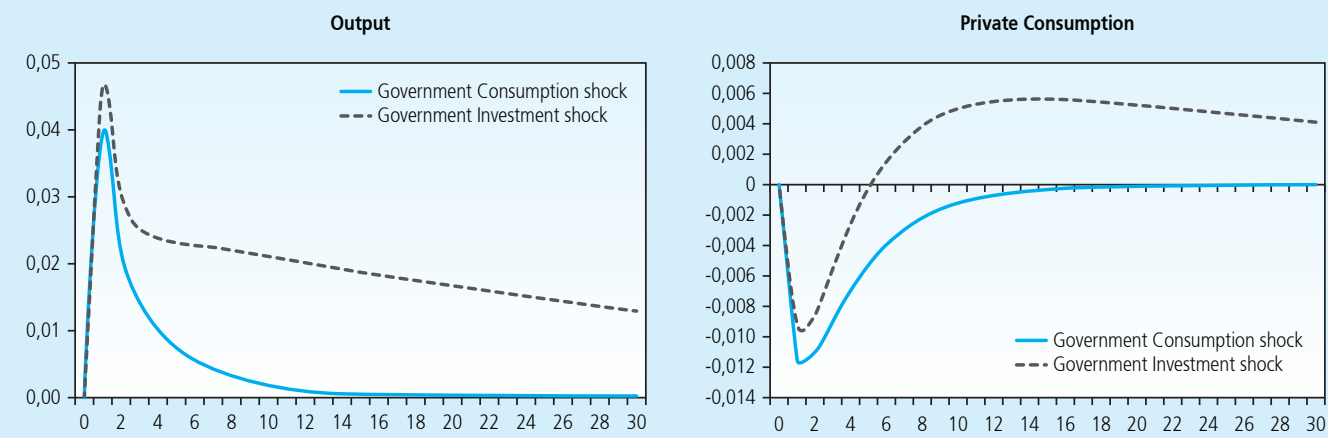

Trade Balance

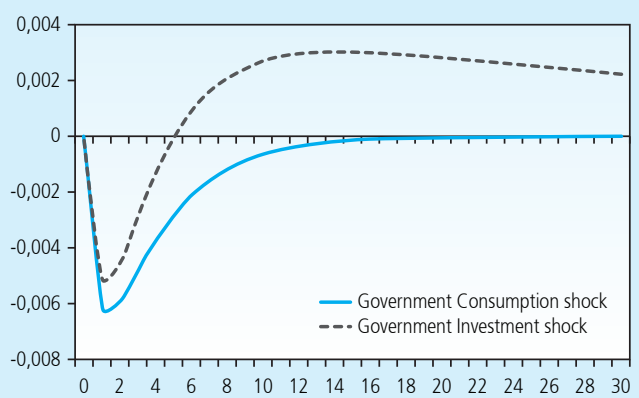

Trade Balance

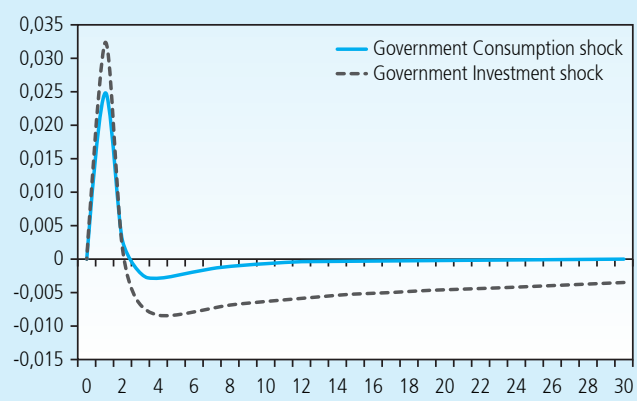

Terms of Trade

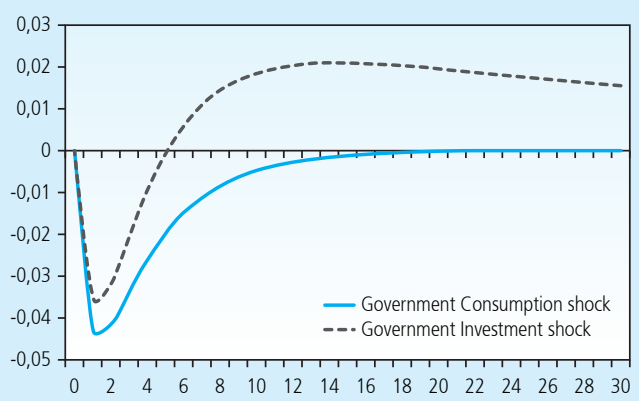

Welfare

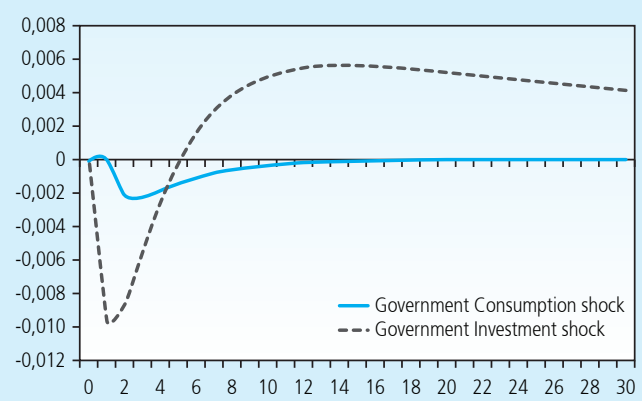

Working Time
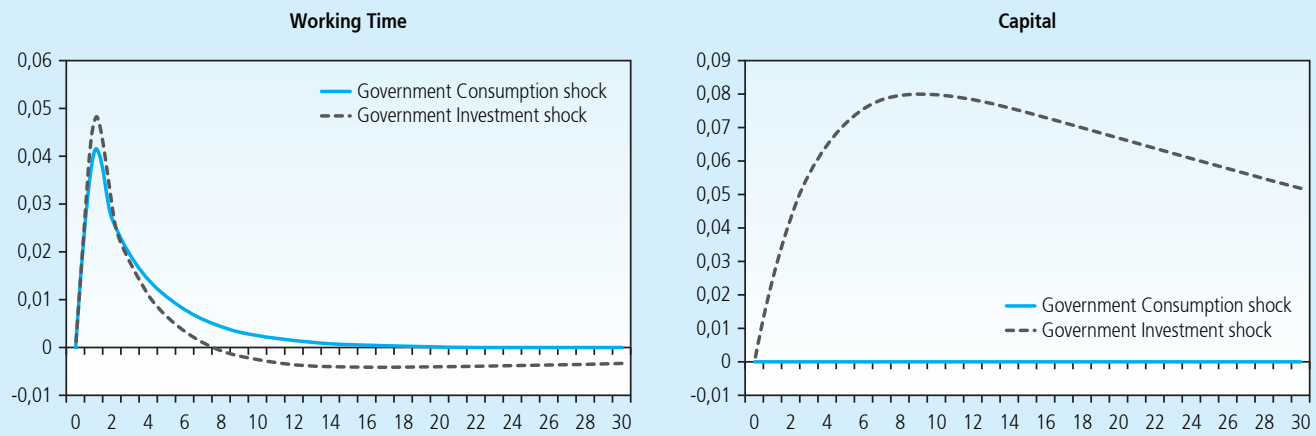

Figure 8. Impact of Fiscal Expansion 
The simulations show that there are two opposing impacts of the increased government consumption. On one hand, higher taxes would cause lower households' consumption and then utility, while working hours would have to be increased to offset the added expense. On the other hand, however, government consumption itself as part of the utility directly increases in welfare.

\begin{tabular}{|c|c|c|c|c|c|c|c|}
\hline \multicolumn{8}{|c|}{$\begin{array}{l}\text { Table } 6 . \\
\text { Output and Welfare Multiplier }\end{array}$} \\
\hline & $\mathrm{CM}$ & $\mathrm{CM}$ & $\mathrm{CM}$ & CM & $\mathrm{CM}$ & \multirow{2}{*}{$\begin{array}{l}\text { NPV Output } \\
\text { Multiplier }\end{array}$} & \multirow{2}{*}{$\begin{array}{l}\text { Welfare } \\
\text { Multiplier }\end{array}$} \\
\hline & 4 & 8 & 12 & 16 & 20 & & \\
\hline Consumption & 0.03 & 0.03 & 0.03 & 0.03 & 0.03 & 0.03 & -0.001 \\
\hline Investment & 0.04 & 0.06 & 0.07 & 0.09 & 0.11 & 0.20 & 0.045 \\
\hline
\end{tabular}

The simulations also show that the welfare multiplier of increased government consumption had a value of -0.001, meaning that households would have to sacrifice Rp0.001 of consumption for each Rp1 the government spent on consumption. The results are consistent with the findings of Ganelli and Tervala (2015), in which increased government consumption reduces household welfare. Nevertheless, the model may also result in a positive welfare multiplier if the ratio of government consumption spending to household consumption ( $v$ parameter) $\geq 0.2$, implying that the minimum ratio of government consumption is $20 \%$ of household consumption to neutralise the adverse effect of increased government consumption.

\subsection{Government Investment}

The simulations show that, in the short run, a $1 \%$ increase in government investment could drive a $0.05 \%$ increase in economic growth above the baseline, representing a larger impact than a corresponding increase in government consumption. In fact, the effect of increased government investment increases in the medium-long term, as shown by the cumulative output multiplier of 0.20 (Table 6). The increase in output originated from two sources, namely an increase in temporary demand and the supply-side effect. Temporary demand would spike due to the direct impact of investment. Meanwhile, the supply-side effect would stem from the availability of public capital (infrastructure), which supports industrial capacity to produce, despite capital gradually depreciating back to the steady state (baseline).

According to this paper, output multiplier is relatively small compared to the study performed by Ganelli and Tervala (2015), but exceeds the values produced in Jha's et al. (2010) paper with a multiplier of 0.19 and Tang et al. (2013) with a multiplier of -0.34 . These findings are consistent with the results of Bom and Ligthart (2013), where public capital is more productive in the long run than the short run. The simulations also show that output would return to the baseline after 10 years, consistent with Leduc and Wilson (2013). 
As shown in Figure 8, consumption would decline in the short run, suppressed by a tax hike to offset the government's investment spending. Furthermore, greater investment spending would improve the terms of trade (ToT), thus bolstering purchasing power and increasing consumption, albeit still negative as an aggregate due to the dominant effect of higher taxes. Similar conditions are observed in the trade balance. Although consumption would experience a decline, large-scale investment would push the trade balance to run a deficit. Nonetheless, in the long run, consumption and the trade balance would rebound as industry became more productive. These findings are consistent with Iwata (2013), who found that a government investment shock would exacerbate the trade balance in the short term but would subsequently improve in the medium-long run.

The simulations also show that the impact of government investment on welfare is 0.05 , implying that households receive a net benefit of Rp0.05 for each additional Rp1 of government investment. The net benefit is an increase in consumption due to greater productivity without having to increase the working hours. In other words, household welfare would improve.

Figure 9 shows the impacts of increased government investment on macroeconomic dynamics. A higher investment value would lead to a more significant increase in output in the short run as well as the medium-long run. The simulations show that to attain a $0.5 \%$ increase in output, more than $10 \%$ increase in investment would be required. The impact on other macro conditions, such as consumption, the trade balance, inflation and welfare also result in similar findings.
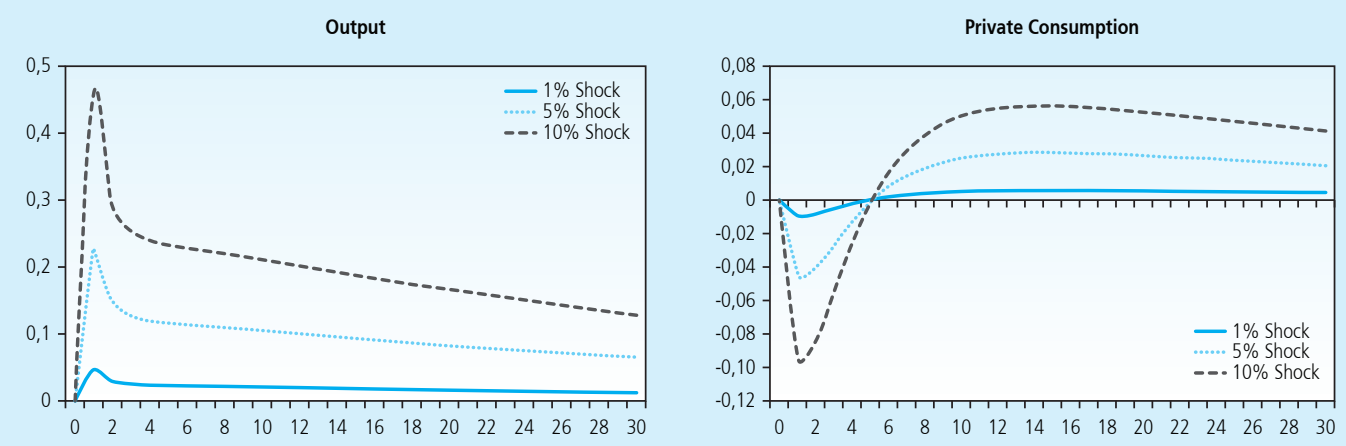

Figure 9.

Impact of Government Investment 


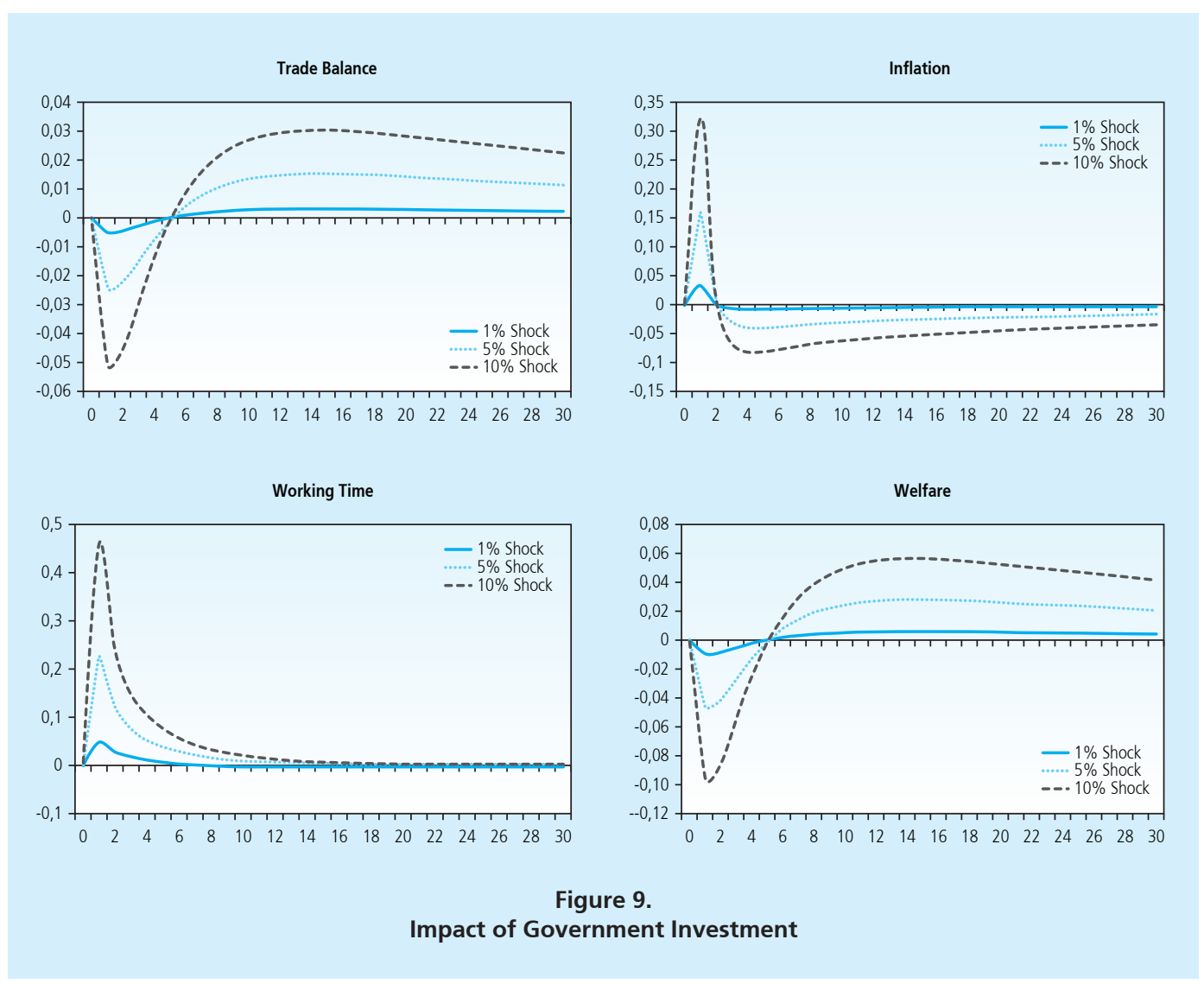

Bom and Ligthart (2014) show that the impact of welfare is sensitive to changes in the output elasticity of public capital. Using the same analysis, however, this study shows that as the new public infrastructure became more productive, the potential increase in economic growth and impact on welfare would also increase (Table 7). Such dynamics indicate that priority infrastructure development should focus on improving productivity in order to provide the most optimal benefits to the economy.

Table 7.

Public Infrastructure Productivity and Multiplier Impact

\begin{tabular}{|c|c|c|c|c|}
\hline \multirow[t]{2}{*}{ Ouput elasticity of public capital } & CM & CM & \multirow{2}{*}{$\begin{array}{l}\text { NPV Output } \\
\text { Multiplier }\end{array}$} & \multirow[t]{2}{*}{ Welfare Multiplier } \\
\hline & 16 & 20 & & \\
\hline$\phi k=0.08$ & 0.05 & 0.05 & 0.08 & 0.00 \\
\hline$\phi k=0.15$ & 0.07 & 0.08 & 0.13 & 0.02 \\
\hline$\phi k=0.20$ & 0.09 & 0.11 & 0.20 & 0.04 \\
\hline$\phi k=0.35$ & 0.12 & 0.15 & 0.28 & 0.07 \\
\hline
\end{tabular}




\section{Conclusions}

One of the most binding constraints facing the Indonesian economy is limited infrastructure in terms of quality and quantity, which has impeded domestic growth and undermined national economic competitiveness. Seeking to overcome the challenges, the Government is currently trying to speed up infrastructure development as part of the ongoing economic structural reforms. The impact of government investment in infrastructure on the economy and public welfare needed to be analyzed quantitatively to provide a more accurate picture of the impact of government investment.

A DSGE model is developed in this paper to estimate the impact of government spending for investment and consumption on output and welfare in Indonesia. In general, the model consists of households, corporations, the government and central bank. Households maximize their utility which is a function of household consumption itself, leisure and government consumption. The corporate sector maximizes profits, where output is a function of technology, the labor force and government capital, while the government is assumed to fully offset consumption and investment spending through higher taxes.

The model is calibrated using parameters consistent with the Indonesian economy. The impulse response functions show that, in the short run, a $1 \%$ increase of government consumption could potentially raise economic growth by $0.04 \%$ above the baseline, primarily driven by increases in terms of aggregate demand, the wealth effect and working hours. Cumulatively, the output multiplier of government consumption is 0.03 . On the other hand, increased government consumption would lead to lower welfare, with a welfare multiplier of -0.001 .

In the short run, a $1 \%$ increase of government investment could potentially raise economic growth by $0.05 \%$ above the baseline. In the medium to long term, however, the impact becomes larger and the output multiplier of government investment is 0.20 . The increase stems from higher temporary demand and the supply-side effect. The higher temporary demand is driven by direct impact of investment, while the supply-side effect originates from the availability of public capital (infrastructure) that continues to support industrial capacity to produce. Increased government investment would also improve welfare, with a welfare multiplier of 0.05 , due to more consumption because of increased productivity without additional working hours, which would improve household welfare.

The simulations of the DSGE model built in this paper shows that government policy to stimulate the economy would be greatly more effective through investment rather than consumption. Based on the figures produced by the simulations, the recent structural reforms implemented by the government, one of which is through increased government investment and less government consumption, including subsidies, are expected to have a significant and positive impact on the national economy. 


\section{REFERENCES}

Anugrah, D. F., Rakhman, R. N., Anglingkusumo, R., Fawaqa, L., \& Oseva, J. (2015). Growth Diagnostic Banten.

Aschauer, D. A. (2000). Aschauer 2000. Economic Development and Cultural Change, 48(2), $391-406$.

Bom, P. R. D., \& Ligthart, J. E. (2014). Public infrastructure investment, output dynamics, and balanced budget fiscal rules. Journal of Economic Dynamics \& Control, 40, 334-354.

Calvo, G. A. (1983). Staggered prices in a utility maximizing framework. Journal of Monetary Economics, 12, 383-398.

Cooley, E. (1995). Frontiers of Business Cycle Research. Princeton University Press.

Gali, J., \& Monacelli, T. (2005). Monetary Policy and Exchange Rate Volatility In A Small Open Economy. Review of Economic Studies, 72(252), 707-734.

Ganelli, G., \& Tervala, J. (2015). The Welfare Multiplier of Public Infrastructure Investment (No. 16/40).

Harmanta, Purwanto, N. M. A., \& Oktiyanto, F. (2012). Sektor Perbankan dalam Model DSGE.

Harmanta, Purwanto, N. M. A., Rachmanto, A., \& Oktiyanto, F. (2013). Penyempurnaan Pemodelan Financial Frictions pada Model DSGE-Bank Indonesia.

Harmanta, Rachmanto, A., Oktiyanto, F., \& Idham. (2014). Interbank Market with DSGE Model.

IMF. (2014). World Economic Outlook: Legacies, Clouds and Uncertainties. Washington, DC: IMF.

Iwata, Y. (2013). Two fiscal policy puzzles revisited: New evidence and an explanation. Journal of International Money and Finance, 33, 188-207.

Jha, S., Mallick, S., Park, D., \& Quising, P. (2010). Effectiveness of countercyclical fiscal policy: Timeseries evidence from developing Asia (No. 211).

Kahn, R. F. (1931). The Relation of Home Investment to Unemployment. The Economic Journal, 41(162), 173-198.

Kementerian Perencanaan Pembangunan Nasional/Badan Perencanaan Pembangunan Nasional. (2014). Rencana Pembangunan Jangka Menengah Nasional 2015-2019. 
Keynes, J. M. (1936). Keynes 1936 The General Theory of Employment, Interest and Money". Book III Chapter 10. London: Macmillan \& Co.

Leduc, S., \& Wilson, D. (2013). Roads to Prosperity or Bridge to Nowhere? Theory and Evidence on the Impact of Public Infrastructure Investment. NBER Macroeconomics Annual, 27, 89-142.

Obstfeld, M., \& K., R. (1998). Risk and exchange rates (No. 6694).

Quintana, P. G., \& M.N., J. (2012). Bayesian Estimation of DSGE (No. 12-4). Philadelphia.

Rodrik, D. (2015). Structural Reform and Greece: Lessons from Other Lands. Retrieved from http://drodrik.scholar.harvard.edu/links/structuralreform-\%0Agreecelessons-other-lands.

Sin, J. (2016). The Fiscal Multiplier in a Small Open Economy: The Role of Liquidity Frictions.

Tabor, S. R. (2015). Constraints to Indonesia's Economic Growth (No. 10).

Tang, H. C., Liu, P., \& Cheung, E. C. (2013). Changing Impact of Fiscal Policy on Selected ASEAN Countries. Journal of Asian Economics, 24, 103-116.

Tjahjono, E. D., Harmanta, \& Waluyo, J. (2009). Bank Indonesia Structural Macromodel (BISMA). Tjahjono, E. D., \& Waluyo, J. (2010). Pemodelan Banking dan Financial Accelerator pada Model DSGE.

World Economic Forum. (2016). Global Competitiveness Index 2016-2017. Geneva. 